\title{
PROPOSAL FOR MEASURING THE MOVEMENT OF A LARGE IGE SHEET BY OBSERVING RADIO ECHOES
}

\author{
By J. F. Nye, R. G. Kyte and D. C. Threlfall* \\ (H. H. Wills Physics Laboratory, University of Bristol, Bristol, England)
}

\begin{abstract}
The proposed method is to use a radio-echo sounder located on the surface of the ice sheet and to record the shape of the pulses returned from the rock bed. If the instrument is moved horizontally, the shape of the returning pulse will change, large differences occurring in horizontal distances of the order of the wavelength of the radiation, say $5 \mathrm{~m}$. The spatial pattern of this variation, being largely determined by the details of the reflecting rock bed, is expected to remain fixed in position while the ice moves. It thus forms a fixed reference against which ice movement can be measured at places far removed from fixed landmarks. Analogue experiments in the laboratory, using ultrasonic waves in air in place of radio waves in ice, suggest that it should be easy to detect a movement of $\lambda / 10,0.5 \mathrm{~m}$, and, with further refinement, much smaller movements. A field test is in preparation.
\end{abstract}

Résumé. Propositions pour la mesure du mouvement d'une grande calotte de glace par l'observation d'echos-radio. La méthode proposée consiste à utiliser un appareil sondeur par écho-radio implanté sur la surface de la calotte et d'enregistrer la forme des impulsions réfléchies par le lit rocheux. Si l'on déplace l'instrument horizontalement, la forme des impulsions renvoyées change, des différences importantes se produisant pour des distances horizontales d'un ordre de grandeur équivalent à la longueur d'onde de l'émission, c'est à dire $5 \mathrm{~m}$. La physionomie dans l'espace de ces variations étant largement déterminée par les détails du lit rocheux réfléchissant, on s'attend à ce qu'elle reste fixe en position lorsque la glace se meut. Elle forme donc une référence fixe par rapport à laquelle le mouvement de la glace peut-être mesuré en des lieux très éloignés d'un rocher fixe déglacé. Des expériences analogiques en laboratoire, utilisant des ondes ultrasoniques dans l'air à la place des ondes radio dans la glace, permettent de supposer qu'il serait facile de déceler un mouvement de $\lambda / 10$, soit $0,5 \mathrm{~m}$, et, avec quelques perfectionnements, des mouvements beaucoup plus faibles. Une expérimentation sur le terrain est en préparation.

Zusammenfassung. Ein Vorschlag zur Messung der Bewegung von grossen Eisschilden durch Beobactung von Radarechos. Die vorgeschlagene Methode besteht darin, ein Radarechogerät auf der Oberfläche eines Eisschildes aufzustellen und die Form der vom Felsuntergrund reflektierten Impulse aufzuzeichnen. Bei horizontaler Bewegung des Instrumentes wird sich die Form des Echos verändern, wobei grosse Differenzen sich bei Horizontalentfernungen in der Grössenordnung der Wellenlänge der Strahlung, z. B. 5 m, auftreten werden. Die räumliche Verteilung dieser Änderungen, die stark von der Topographie des reflektierenden Felsuntergrundes abhängt, wird als gleichbleibend angenommen, während sich das Eisbewegt. Dadurch entsteht ein festes Bezugssystem, gegen das die Eisbewegung fernab von festen Landmarken gemessen werden kann. Analoge Laborversuche unter Verwendens von Ultraschallwellen in Luft statt Radiowellen in Eis deuten an, dass es leicht sein sollte, Bewegungen von $\lambda / 10,0.5 \mathrm{~m}$, zu erkennen, und-mit weiterer Verfeinerung - noch viel kleinere Bewegungen. Ein Feldversuch ist in Vorbereitung.

In the standard method of radio-echo sounding of polar ice masses (Robin and others, 1969) a pulse is sent out from a transmitter at or above the upper surface of the ice and the observer measures the time delay of the echo returned from the bottom surface to a receiver very close to, or coincident with, the transmitter. The returning signal is a distorted version of the outgoing pulse, the main source of the distortion being the fact that reflexion has occurred at a rough surface (Berry, I972). If the transmitter and receiver are moved sideways together, the time delay of the onset of the echo, being determined by the range, changes slowly, but, in contrast, the form of the returning signal, being determined by diffraction, changes very much more quickly. This change in form is called the spatial fading pattern. That the echo from the bottom of the ice changes in strength as one moves through distances of the order of the radio wavelength was reported as long ago as ig64 (Bailey and others, 1964).

As time goes on, the ice moves under gravity; its top surface moves horizontally and vertically relative to the bedrock by distortion within the ice, and this may or may not be accompanied by sliding of the ice over the bedrock. If the surface reflecting the radio waves is the fixed, rough bedrock, and if, as seems reasonable, we can ignore distortions of the signal produced by the movement of the transmitting medium, the spatial fading pattern will be

* Now at Churchill College, Cambridge, England. 
unaltered and will remain fixed in position. Observation of the position of a marker on the ice surface relative to the fading pattern therefore provides, in principle, a method of measuring the displacement of the marker, and therefore of measuring the velocity of the ice. The method might be used in the interior of Antarctica, for example, at places far removed from fixed landmarks.

In particular localities it could be that the signal apparently returned from the bottom of the ice is partly or wholly due to scattering by a layer of rock debris entrained in the ice very near the bottom, within the pulse length. If there were forward movement in this diffracting layer the method would, at best, measure the relative velocity between it and the top surface. It is more likely that the relative motion between the partially reflecting layer and the partially reflecting rock bed, not resolved from it in range, would so change the shape of the returning pulse that the spatial fading pattern would not remain recognizably the same as time went on; this would be an interesting observation but it would of course vitiate the method. However, it is generally thought, on the basis of the current theory of glacier sliding (Weertman, r957), that in those parts of Antarctica where the basal ice is below the melting point, there is no sliding of the ice over the bedrock. Sliding will only occur where the melting point is reached. It is also thought, on the basis of current theories of heat flow within the ice sheet (Budd and others, I970), that most of the bottom is below the melting point. Therefore, over most of the continent the ice is not sliding; so even if in some places there is significant scattering by a layer of rock debris near the bottom, the layer will only be moving and turning relatively slowly and will not interfere seriously with the method. The most unfavourable areas would be those with the bottom at the melting point and a heavy layer of basal moraine overlying the bedrock.

With an outgoing pulse of fixed shape the information received back at any point is represented by a function of a single variable, say the voltage at the aerial terminals as a function of time. Additional information could be obtained by changing the form of the transmitted pulse, by changing the polarization of the transmitting aerial and, independently, the polarization of the receiving aerial, and by changing the directional characteristics of the aerials. In the most general sense the fading pattern is the spatial variation of all this information. Thus, provided at least some of the information varies sufficiently fast with position, it provides the sensitive measure that is needed.

One reason why the method suggested here has not been exploited may have been the belief that, because the wave paths contain a very large number of wavelengths, the fading pattern observed would be very sensitive to slight changes in frequency and bandwidth of the transmitted pulse, and thus the equipment would need to be extremely stable in performance over long periods. This does not seem to be so. The pulses commonly used are of the order of ten wavelengths long. The pulses scattered from two different points on the bed will not interfere if the total path difference between them exceeds $10 \lambda, \lambda$ being the wavelength in ice. Therefore the returning pulse is formed by the interference of many pulses with mutual path differences of less than $10 \lambda$. When two waves differ in path by $10 \lambda$ their interference pattern will be seriously changed, maxima becoming minima, if their wavelength is changed by $5 \%$. Thus, by this argument a frequency change of at least $5 \%$ would be needed before the form of the returning pulse at any given place, and therefore the spatial fading pattern, changed by a large amount. The argument is for a non-dispersive medium, and it is confirmed by the experimental observations described below on ultrasonic waves in air, which is virtually nondispersive.

On the other hand, since a polar ice sheet is a non-uniform and slightly dispersive medium for radio waves (Robin and others (1969, p. 459) take $5 \times 10^{-4} \mathrm{MHz}^{-1}$ as the maximum possible value of $\mathrm{d} n / \mathrm{d} f$ in their frequency range, where $n$ is the refractive index and $f$ is the frequency), a change of frequency could have some effect on the form, and therefore on the length, of the slightly curved ray path to any particular point on the bed. This and other 
effects of dispersion, arising not only from the medium itself but also from the reflexion process, would make the fading pattern more sensitive to frequency than the argument for a nondispersive medium would imply. It may be doubted whether these hypothetical dispersion effects are large enough to demand unusual frequency stability in the equipment, bearing in mind that control and measurement of frequency, even at a remote station, is not a difficult operation; but one cannot be completely sure of this until a field test is made.

If the station is moved vertically, rather than horizontally, the delay time of the returning pulse will change and, in addition, the pulse will change in form because the diffraction geometry is altered. There are two ways in which vertical movement can take place: either the aerial can be raised above the snow surface, or the position of the snow surface itself can change, carrying the aerial with it. A change in the height of the aerial above the snow surface will have an effect on the radiation pattern from the aerial in the ice, and will therefore change the area of the bed contributing to the returned pulse. If, on the other hand, the snow surface and the aerial move together, the radiation pattern in the ice will not change. This second type of movement is equivalent to moving an aerial vertically in a single medium of ice. The experiments described below were done in one medium, and indicate that, in this case, the form of the received signal changes faster horizontally than vertically. For the purpose of using the fading pattern to measure the horizontal movement of the ice this is convenient, but not essential. On the other hand, the change in the vertical direction might possibly provide a useful means of locating position vertically. From the point of view of determining whether the Antarctic ice sheet is growing or diminishing it is of course more direct to measure the changes of elevation of its surface than to infer them from the rate of outward movement of the ice combined with knowledge of the rate of accumulation.

A possibility exists of measuring not only the horizontal velocity of the ice at the surface but also the velocity of the ice at depth. This arises because radio-echo records of ice sheets show echoes not only from the rock bed but also from internal layering (Robin and others, I969, p. 494; Robin and others, I970). Each internal reflecting layer will have its own spatial fading pattern. Thus the motion of a surface station relative to the fading pattern from a given layer provides, in principle, a method of measuring the velocity of the surface relative to the layer (and hence the velocity of the layer relative to the rock bed).

To help assess the feasibility of using the spatial fading pattern to measure ice velocities, an analogue of the radio-echo system was set up in the laboratory using ultrasonic pulses in air in place of radio pulses. Lengths were scaled down by a factor of $\mathrm{I} 400$. The velocity of sound in air at $20^{\circ} \mathrm{C}$ being $4.9 \times 10^{5}$ times less than that of radio waves in ice, it follows that times must be scaled up by a factor of $35^{\circ}$. This means that the radio frequency of $35 \mathrm{MHz}$ becomes $100 \mathrm{kHz}$ in the ultrasonic apparatus; the corresponding wavelengths are $4.8 \mathrm{~m}$ for radio waves in ice and $3.4 \mathrm{~mm}$ for ultrasonics in air. The attenuation of $35 \mathrm{MHz}$ radio waves in $\mathrm{I} 400 \mathrm{~m}$ of ice at $-20^{\circ} \mathrm{C}$ is $20 \mathrm{~dB}$ (Robin and others, 1969 , p. 474) compared with 3 to $4 \mathrm{~dB}$, depending on the humidity, for the attenuation of $100 \mathrm{kHz}$ ultrasonic waves in $\mathrm{I} \mathrm{m}$ of laboratory air (Pöhlmann, I96i ; Kneser, I965, p. I 7 I-73). The ultrasonic transmitter and receiver, based on a design by Wyndham (1968), were made so that the pulse shape and pulse repetition rate matched those of the Scott Polar Research Institute Mark II radio-echo apparatus; the polar diagram of the ultrasonic transducers $( \pm 30$ deg fore and aft and \pm Io deg sideways measured to the half-power level) was made to match that of the S.P.R.I. equipment as it would be if measured in ice rather than in air. In short, the main features of the radio instrument are represented in the analogue. The analogy is closest when the radio equipment is at the ice surface rather than in an aircraft, since the air-ice surface has, at present, no counterpart in the ultrasonic model. Of course, the ultrasonic apparatus, generating scalar (longitudinal) waves, cannot in principle model the polarization effects associated with the vector electromagnetic wave. 
The rough bed of the Antarctic ice sheet was simulated in the laboratory by a sheet of aluminium foil laid on the floor and suitably crumpled (Fig. I); we tried to make it so that when viewed from a height of $\mathrm{I} \mathrm{m}$ it would appear similar to the bed of an ice sheet seen from a height of $\mathrm{I} 400 \mathrm{~m}$. The ultrasonic apparatus was made to travel in a horizontal straight line $65 \mathrm{~cm}$ above it. The part of the returning pulse that is most sensitive to the position of the instrument is probably the tail, which represents radiation diffracted from more distant parts of the rough surface. But in our apparatus, with everything held fixed, there was still an unwanted time fluctuation in the tail of the returning pulse which was probably due to draughts in the room. For this reason we studied instead the maximum of the returning pulse, which was much more stable. In Figures 2 to 4 the horizontal position of the instrument is plotted horizontally. At each position the positive-going part of the returned pulse is ignored; the negative-going part produces a time-varying vertical displacement of the spot on the cathode-ray tube, which is seen as a vertical line whose height corresponds to the maximum of the returned pulse. Thus the upper boundary of the bright region represents a plot of the height of the maximum of the returned pulse versus position (the lowest $2 \mathrm{~cm}$ of the record is blanked off). Figures $2 \mathrm{a}$ and $2 \mathrm{~b}$ are repeated runs over the same line; the differences between

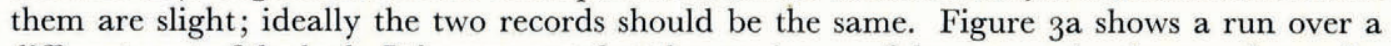
different part of the bed. It is apparent that the maximum of the returned pulse can change by large amounts in a distance of one wavelength; indeed at some places on the record the edge of the bright region is almost vertical on the scale shown. This is the main observation we wish to report, since it implies great sensitivity if used for the measurement of ice movement. The same point is made in a different way by comparing Figures $3 \mathrm{a}, \mathrm{b}$ and $\mathrm{c}$, which show three parallel runs each separated from the next by half a wavelength. In Figures $3 \mathrm{a}$ and $3 \mathrm{~b}$ common features can be identified, but there is a large change in the pattern. Similarly with Figures $3 \mathrm{~b}$ and $3 \mathrm{c}$; but Figures $3 \mathrm{a}$ and $3 \mathrm{c}$ are quite different. We may remark that the autocorrelation function of the record in Figure 4 a falls to zero at a distance of 1.2 wavelengths; however, the sensitivity to displacement can be much greater than the autocorrelation function by itself may suggest, because if the record is nearly vertical at a single point this point could be used to give great sensitivity to displacement regardless of the statistics of the record as a whole.

Other experiments, not illustrated here, showed that after a vertical displacement of two wavelengths the main features of the pattern were still preserved. Thus, as mentioned above, the change is much more rapid in the horizontal than in the vertical direction. When the frequency of the transmitted pulse was changed by $3 \%$, a relatively large amount, the pattern was changed in detail but the major features remained recognizably the same (Fig. $4 \mathrm{a}, \mathrm{b}$ and c). This is in accord with the theoretical expectation mentioned earlier for a non-dispersive medium. We should also mention that when the frequency of the transmitted pulse was changed there was an equal proportional change in the pulse's bandwidth (the receiver having a relatively large bandwidth).

Figures 2 to 4 suggest that if the ultrasonic fading pattern were used for position finding in the laboratory it would be quite easy to attain a precision of $\lambda / 10$, and with further refinement one could expect to achieve much more than this, say $\lambda /$ ı oo or better. In the field, using radio waves, one might be able to work on the tail of the returning echo and so gain an advantage in precision; on the other hand, if the bottom surface in the locality chosen happened to be smoother (in some appropriate sense) than the one used in the laboratory, the precision would be correspondingly reduced. No doubt there would be additional adverse factors in the field.

A possible field procedure would be first to set up a line on the surface in the direction of the expected ice motion and then to establish reproducibility by repeated runs over it. Parallel runs separated by, say, $\lambda / 10=0.5 \mathrm{~m}$ would also be made. The patterns, or various selected features of them, would then be periodically remeasured and examined for displacement. For example, if the speed of the ice were $10 \mathrm{~m} \mathrm{a}^{-1}$, a movement of $\lambda / 10=0.5 \mathrm{~m}$ would occur in 
$20 \mathrm{~d}$ and a movement of $\lambda / \mathrm{roo}$ in $2 \mathrm{~d}$. These figures suggest that it might be possible to detect and measure movement during the residence time of a party at the station, without the need for repeated visits.

Dr M. E. R. Walford and Dr C. W. M. Swithinbank plan to make a field test of the method during the 1971/72 season with the British Antarctic Survey working in the Antarctic Peninsula. If this is successful the method could offer notable advantages for work on the main Antarctic plateau. For example, in the International Antarctic Glaciological Project it is at present proposed to measure the movement of the ice on the Antarctic plateau by first making trilateration surveys inland from the coast to establish the positions of inland stations, and then repeating the surveys after an interval. The random error in position is expected to be about $3 \mathrm{~m}$ in $\mathrm{I}$ ooo $\mathrm{km}$ (Budd, private communication). The systematic error in position is estimated at about $10 \mathrm{~m}$ in $\mathrm{I}$ ooo $\mathrm{km}$, but if the measurements were repeated in precisely the same way the systematic error in the difference should be less than this. For example, the line from Wilkes to Vostok is about I $300 \mathrm{~km}$ long and so the error expected is about 4 to $\mathrm{I} 3 \mathrm{~m}$. The ice velocity expected in the region near Vostok is as low as $2 \mathrm{~m} \mathrm{a}^{-1}$. Hence remeasurement after 5 to io years would just begin to show significant results. As an example of another possible method (Budd, private communication) the U.S. PAGEOS geodetic position system has already operated at many Antarctic coastal stations, the accuracy expected in the distance between stations being about $5 \mathrm{~m}$. Thus if this method were used for the Vostok region significant movement would become apparent after several years. The spatial fading pattern method, if used in the same region, would show a movement of $\lambda / 10$ in $90 \mathrm{~d}$ and a movement of $\lambda / \mathrm{roo}$ in $9 \mathrm{~d}$. Therefore, if field tests are successful, the method offers the prospect of providing ice velocity measurements quickly, with fairly simple equipment and without the need for expensive traverses. Compared with satellite and other systems using microwaves and lasers it has the ultimate advantage that its fixed reference, the rock bottom, is the closest possible, and the ultimate disadvantage that attenuation in the ice sets a stringent limit on the smallest wavelength that can be used.

Note added in proof. 27 July 1972. The Antarctic field test was successful and gave a precision of $\lambda /$ roo (Walford, 1972) even though a fairly crude technique had to be used. A modification of the method described in the present paper, to make the apparatus equally sensitive to vertical movement, and therefore to changes in ice thickness, is described by Nye and others (in press).

\section{Acknowledgements}

We should like to thank Professor D. Chesterman for a helpful introductory discussion of echo-sounding problems and Mr L. Wallis for his technical help in constructing the ultrasonic apparatus. We are also grateful to Dr M. E. R. Walford and Dr M. V. Berry for their advice during the experiments and for their valuable comments on the manuscript.

MS. received 22 November 197 I and in revised form ${ }_{3}$ March 1972

\section{REFERENCES}

Bailey, J. T., and others. 1964. Radio echo sounding of polar ice sheets, by J. T. Bailey, S. Evans and G. de Q. Robin. Nature, Vol. 204, No. 4957, p. 420-21.

Berry, M. V. 1972. On deducing the form of surfaces from their diffracted echoes. Fournal of Physics, A, Vol. 5, No. 2, p. 272-91.

Budd, W. F., and others. [1970.] The extent of basal melting in Antarctica, by W. [F.] Budd, D. Jenssen and U. Radok. Polarforschung, Bd. 6, Jahrg. 39, Nr. r, 1969, p. 293-306.

Kneser, H. O. 1965 . Relaxation processes in gases. (In Mason, W. P., ed. Physical acoustics: principles and methods. Vol. 2, Part A. New York, Academic Press, p. 133-202.) 
Nye, J. F., and others. In press. A proposed method of measuring the change in thickness of the Antarctic ice sheet, by J. F. Nye, M. V. Berry and M. E. R. Walford. Nature.

Pöhlmann, W. 1961. Die Schallabsorption von Luft verschiedener Feuchtigkeit zwischen ro und $100 \mathrm{kHz}$ (In Cremer, L., ed. Proceedings of the third International Congress on Acoustics, Stuttgart, 1959. Amsterdam, etc., Elsevier Publishing Co., Vol. 1, p. 532-35.)

Robin, G. de Q., and others. I 969 . Interpretation of radio echo sounding in polar ice sheets, by G. de Q. Robin, S. Evans and J. T. Bailey. Philosophical Transactions of the Royal Society, Vol. 265A, No. I 166, p. 437-505.

Robin, G. de Q., and others. 1970. Radio echo exploration of the Antarctic ice sheet, by G. de Q. Robin, C. W. M. Swithinbank and B. M. E. Smith. (In [Union Géodésique et Géophysique Internationale. Association Internationale d'Hydrologie Scientifique.] [International Council of Scientific Unions. Scientific Committee on Antarctic Research. International Association of Scientific Hydrology. Commission of Snow and Ice.] International Symposium on Antarctic Glaciological Exploration (ISAGE), Hanover, New Hampshire, U.S.A., 3-7 September 1968, p. 97-I I 5.)

Walford, M. E. R. 1972. Glacier movement measured with a radio echo technique. Nature, Vol. 239, No. 5367, p.93-95.

Weertman, J. 1957. On the sliding of glaciers. Journal of Glaciology, Vol. 3, No. 21, p. 33-38.

Wyndham, B. A. 1968. Demonstrating radar using sonar. I. Circuit details. Wireless World, Vol. 74, No. I394, p. $248-5$ I. 